\title{
A Response to Critics of Family Planning Programs
}

Sharply rising energy and food prices have once again raised the specter of the human population outstripping the planet's natural resources. Ever since Malthus, pessimists have believed that mankind is doomed due to overpopulation and overconsumption, while optimists have argued that technological innovation will improve standards of living and that population growth is at most a minor issue. ${ }^{1,2}$ While this renewed debate at the global level receives widespread media attention, another less visible but equally important discussion of the impact of demographic trends and policy options is under way among the leaders of the least- developed countries. A large majority of these leaders agree that population growth and birthrates are too high. ${ }^{3}$ Potential adverse effects include poor health among women and children, slow economic growth and poverty, overcrowded schools and clinics and an overburdened infrastructure, as well as the depletion of environmental resources. ${ }^{4}$ In addition, high unemployment and inequality among rapidly growing young populations may contribute to the spread of political violence and civil strife..$^{5-7}$

In many developing countries, these concerns have led to action. Since the 1960s, alongside efforts to increase educational opportunity and improve health conditions, the main policy response to concern about rapid population growth has been the implementation of voluntary family planning programs* that provide information about, and access to, contraceptives. This policy has permitted women and men to control their reproductive lives and avoid unwanted childbearing. Only in rare cases, most notably in China and briefly in India, has coercion been used.

The choice of voluntary family planning programs as the principal policy instrument to reduce fertility has been based largely on the documentation of a substantial level of unwanted childbearing and an unsatisfied demand for contraception. ${ }^{8,9}$ Family planning programs provide a winwin solution: The welfare of individual women and children is improved, and the national economy and environment benefit. The international consensus on this issue is reflected in the Millennium Development Goals, specifically in Target 5.b.-to provide universal access to reproductive health by 2015 and to reduce the unmet need for family planning. ${ }^{10}$

*Since the landmark International Conference on Population and Development (ICPD) in Cairo in 1994, family planning has been included in the broader concept of reproductive health. Moreover, in the years since the ICPD, that concept has been broadened even further to incorporate sexual health and sexual and reproductive rights.
Despite this long-standing and widely accepted rationale for voluntary family planning programs, funding for these programs has declined by 30\% since the mid1990s. ${ }^{11}$ A number of reasons can be cited, including the (in our view, mistaken) claim that the need for such programs has declined, given the significant progress made in reducing fertility, especially in Asia and Latin America; donor fatigue; persistent opposition fhrom conservative governments and institutions (in particular the Bush administration and the Vatican); and the need for resources to address other pressing problems, such as the AIDS epidemic. Unfortunately, this neglect is encouraged by a small group of influential and determined critics of family planning, whose superficially plausible arguments encourage policymakers and donors to reduce investments in contraceptive services and supplies.

The literature is thin on rebuttals to these critics, although it contains many statements on the benefits of family planning programs. ${ }^{9,12,13}$ Our objective is to set the record straight on several central issues in this debate, to show why the most frequently cited critiques of family planning programs are misleading or wrong, and to reestablish a higher priority for family planning on the international agenda.

\section{Critique: Family planning programs have little or no effect on fertility. ${ }^{14,15}$}

Response: This argument is based on the view of a number of economists that couples have the number of children they want and can afford. ${ }^{14,16,17}$ It assumes that parents select their family size in more or less the same way they choose consumer durables. High fertility in poor countries is considered to be the result of couples wanting many children to help with household chores and agricultural work and to provide for them in old age. Family planning costs are often treated as a minor issue in parents' decision making.

The real world is less simple. In the developing world, 137 million women who don't want to get pregnant are not practicing contraception. ${ }^{13}$ The key cause of this unmet need for contraception is that contraception is often quite costly to individuals in terms of commodities (pills, condoms, IUDs, etc.), transportation, and provider fees for contraceptives and health care services, even when subsidies are provided by the government. In addition, there are significant noneconomic costs, such as health concerns, social disapproval and spousal resistance, as well as unnecessary medical barriers (e.g., requiring a doc-

\section{By John Bongaarts and Steven W. Sinding}

John Bongaarts is vice president and distinguished scholar of the Population Council. Steven W. Sinding is a senior fellow of the Guttmacher Institute. He is the retired director general of the International Planned Parenthood Federation. 
tor instead of a nurse or other trained health care worker to provide certain contraceptives. ${ }^{8}$ This unmet need is in turn responsible for most of the 76 million unplanned pregnancies that occur each year. ${ }^{13}$ About half of these pregnancies end in abortion and the other half end in births; both contribute unnecessarily to health risks for mothers and children, to the cost of raising families and to the adverse impact of population growth.

The existence of a high level of unmet need for contraception convinced many policymakers that family planning programs would be acceptable and effective. This conclusion is supported by results of such experiments as the one conducted in the Matlab district of rural Bangladesh. ${ }^{18}$ When this experiment began in the 1970s, Bangladesh was one of the world's poorest and least developed countries, and there was considerable skepticism that couples would be motivated to have smaller families.

Comprehensive family planning and reproductive health services were provided in the treatment area of the experiment. A wide choice of methods was offered, highquality referral and follow-up were provided and a new cadre of well-trained women (called Family Welfare Visitors) replaced traditional birth attendants as service providers. Contraceptive use rose sharply as these improvements were implemented. No such change was observed in the comparison area. The differences between the two areas in contraceptive use and fertility were maintained over time, thus convincing the Bangladesh government to adopt the Matlab model as its national family planning strategy.

The result was a 20-year fall in the fertility of Bangladesh, from more than six children per woman to nearly three, as contraceptive use in the same period rose from fewer than $10 \%$ of married women to more than $50 \%$. Parts of Bangladesh now have fertility significantly below three births per woman. ${ }^{19}$ The success of the Matlab experiment, and the subsequent success of Bangladesh's national family planning program, demonstrated that appropriately designed services can reduce unmet need for contraception and fertility, even in traditional settings.

Another convincing illustration of the impact of voluntary family planning is the program introduced in Iran in 1989. Free contraceptive services were provided throughout the country by an extensive network of village health workers. ${ }^{20}$ The response was immediate and large: Fertility declined from more than five births per woman in the late 1980s to just two in 2000. No other country experienced a decline of that magnitude during the 1990s. While it is likely that some fertility change would have occurred without these new services, the unprecedented pace of the fertility decline argues for a substantial impact of the program.

Many other countries have introduced family planning programs since the 1960s. The resources devoted to them-and hence their fertility impact-have varied widely. The aggregate effect of all these efforts has been substantial: Fertility declined in the developing world from more than six to fewer than four births per woman be- tween 1960-1965 and 1985-1990, and almost half of that decline-43\%-is attributable to family planning programs. ${ }^{21}$ Voluntary family planning programs are intended to reduce the number of unplanned pregnancies, but they also legitimize and diffuse the idea of smaller families, thus accelerating the transition to lower fertility. This is important in countries where women still want large families. In such populations, there will have to be declines in the number of children desired before sustained fertility decline can occur. Desired family size is highly responsive to improvements in human development, in particular in female education and child survival. ${ }^{22-24}$ This conclusion is strongly supported by the fact that low fertility has been achieved in some very poor societies, such as Cuba, Sri Lanka and the state of Kerala in India. Although poor, these populations have had high levels of literacy and female empowerment and low infant and child mortality, along with access to family planning. The most effective public policies to reduce high fertility, therefore, have pursued two strategies: encouraging human development and strengthening the family planning program. In each case cited above, the government invested heavily in primary health care and free public education for girls and boys through secondary school, thus addressing two of the most powerful determinants of fertility-the reduction of infant mortality and the empowerment of women.

\section{Critique: Fertility declines are under way everywhere, so the population problem has largely been solved and family plan- ning programs are no longer needed. ${ }^{15,25,26}$}

Response: A revolution in reproductive behavior has swept the globe since the 1960s. In the developing world, contraceptive use, once rare, is now widespread, and the average number of births per woman has fallen by half. In most of the industrialized world, already-low fertility has now dropped below the "replacement level" of two children per woman. ${ }^{3}$ These developments have led to claims that the world population explosion is over. ${ }^{25,26}$

Instead of being near the end of the unprecedented population expansion of the past 50 years, human numbers continue to increase by more than 75 million a year, just as has been the case in every year since 1970. The United Nations expects the population of the world to continue to grow until at least 2050, adding 2.7 billion to the 2005 population of 6.5 billion. ${ }^{3}$ Nearly all of this future growth will occur in the developing world, where population size is projected to increase from 5.3 to 7.9 billion between 2005 and 2050. (In contrast, in the developed world, population size is forecast to remain virtually stable until 2050.)

Despite declining fertility rates, large increases in population are expected in Africa (by 1.1 billion), Asia (by 1.3 billion) and Latin America (by 0.2 billion). ${ }^{3}$ There are three reasons for this.

First, the average decline from six to three births per woman still leaves fertility substantially above the twochild level needed to bring about population stabilization. 
With more than two surviving children per woman, every generation is larger than the preceding one; as long as that is the case, population expansion continues.

Second, declines in mortality-historically the main cause of population growth-will almost certainly continue. Higher standards of living, better nutrition, expanded health services and greater investments in public health measures have increased life expectancy by $50 \%$ since 1950, and further improvements are likely.

The final factor is "population momentum," which is the tendency for a population to keep growing even if fertility could immediately be brought to the replacement level of 2.1 births per woman. The reason for this growth is a young population age structure. For example, in SubSaharan Africa, $43 \%$ of the total female population was younger than 15 in $2005 .^{3}$ This large new generation of girls is now entering the childbearing years. Even if each of these women has only two children, they will produce more than enough births to drive population growth for decades to come.

Further large increases in the population of the alreadycrowded developing world are therefore virtually certain. In fact, it is possible that current projections underestimate future growth because they assume steady declines in fertility. This assumption has been proven wrong in a number of countries, particularly in Africa (e.g., Kenya and Ghana), where fertility declines that started in the 1970s, 1980s or 1990s have now stalled. ${ }^{27}$ Even a modest slowdown in the pace of projected fertility decline will produce substantial additional population growth.

\section{Critique: The death toll of the AIDS epidemic makes family planning undesirable and unnecessary. ${ }^{28}$}

Response: By the end of 2006, a cumulative total of about 25 million individuals had died of AIDS. The death toll will reach much higher levels in the future because 33 million individuals are currently infected and many new HIV infections are occurring each year. ${ }^{29}$ By far the largest epidemics are found in southern Africa, where about one in five adults are infected. In contrast, other continents experience infection levels of only a fraction of $1 \%$. The causes of the concentration of the epidemic in one region of Africa include a relatively high frequency of multiple and concurrent sexual partners, low levels of male circumcision, a high prevalence of other STIs and low use of condoms. ${ }^{30}$

A massive global effort has been mounted to reduce infections through prevention programs (which encourage abstinence, reduction in number of partners and increased condom use, as well as VCT and use of family planning by infected women) and to extend the lives of infected individuals with antiretroviral therapy. These prevention efforts are partly responsible for a major recent turning point in the epidemic. ${ }^{30}$ After a period of rapid spread, the epidemic appears to have stabilized in most countries and the proportion of adults infected with HIV is no longer rising and may even be declining. ${ }^{29,30}$

Despite the substantial mortality from AIDS, UN pro- jections for all developing regions, including Africa, predict further large population increases. This is because the annual number of AIDS deaths (two million) is equivalent to just 10 days' growth in the population of the developing world. The population of Sub-Saharan Africa is expected to grow by one billion between 2005 and 2050 (from 0.77 to 1.76 billion). In fact, high AIDS mortality is not expected to cause a decline in the population of any African country between 2005 and 2050. Even with the steady future declines in fertility assumed by the UN, most populations in Sub-Saharan Africa are projected to more than double, several to triple and one (Niger) to quadruple by $2050 .^{3}$

\section{Critique: Family planning programs are not cost-effective. ${ }^{14}$}

Response: Governments compare costs and benefits when determining whether investing in a family planning program is worthwhile. Costs include contraceptive commodities, personnel and the management of a service delivery system. Benefits include improvements in personal well-being (giving a woman control of her body), in health (protection of women and infants from medical risks during pregnancy, delivery and the postpartum period, as well as a reduction in mother-to-child transmission of HIV), in socioeconomic development (more rapid economic growth and lower demands on public budgets), and in reduced pressure on environmental resources (water, arable land, forests).

The data to accurately estimate all these factors are lacking, but the cost-effectiveness of family planning as a health investment is well established. The potential health impact is evident: The 76 million unintended pregnancies in the developing world in 2003 resulted in 184,000 pregnancy-related deaths and 1.8 million infant deaths. ${ }^{31}$ Raising contraceptive use to reduce unintended pregnancies will avert a part of these deaths. The World Bank's Disease Control Priorities Project estimates the cost of family planning at $\$ 100$ per life-year saved. ${ }^{32}$ This is of the same order of magnitude as other health interventions, such as basic sanitation for diarrheal disease, a short course of chemotherapy for TB and condom distribution for HIV prevention. It is worth noting that all these interventions are about 10 times as cost-effective as antiretroviral treatment of AIDS, which currently receives a large proportion of health-related development aid. ${ }^{32}$

Investments in family planning are often also justified on economic and environmental grounds. Rapid population growth and high fertility typically lead to slower economic growth and higher levels of poverty than would otherwise be the case. ${ }^{4}$ Conversely, rapid fertility decline creates a so-called "demographic dividend," which boosts economic growth for a few decades by increasing the size of the labor force relative to both young and old dependents and by stimulating savings.

Governments of poor, largely agricultural countries also realize that rising food demand caused by population growth (compounded by rising incomes, as, for example, 
is now occurring in India and China) will be difficult to meet as environmental constraints on production grow over time. Nearly everywhere, the most productive land is already used for agriculture or covered by man-made structures, the best river sites have been dammed and water shortages are often acute. The newest threat to food production comes from steeply rising energy prices. Energy is an integral part of every step in the food production system-cultivation, harvesting, transportation, refrigeration, packaging and distribution-and prices of hydrocarbonbased fertilizer and pesticides have skyrocketed. In such circumstances, raising agricultural production and standards of living while the population more than doubles is highly problematic.

Improved national security is yet another potential benefit from lower fertility. High fertility in many countries of Africa and the Middle East has resulted in very young age structures, with up to half the population younger than 15 . The inability of many of these countries to provide adequate educational and employment opportunities is a socially and politically volatile mix, often producing frustrated youth who are potentially susceptible to the appeals of radical political ideologies. ${ }^{6,7}$

\section{Critique: Family planning programs at best have made women the instruments of population control policies and, at worst, have been coercive. ${ }^{15,33}$}

Response: In the 1960s and 1970s, evidence that family planning programs could help meet an existing demand for contraception and reduce fertility was still limited. Pilot projects in places like Taiwan and Korea were successful, and surveys in a number of countries documented a demand for contraception. ${ }^{34}$ This evidence persuaded proponents of voluntary family planning programs that scaling up would be effective. Two major international donors, USAID and UNFPA, also advocated this approach. However, skeptics claimed that couples were insufficiently motivated to adopt contraception and pointed to a lack of fertility change in many developing countries, including India and Pakistan, where very early and poorly designed family planning programs had produced disappointing results. ${ }^{35}$

Especially in Asia, where concern about rapid population growth was most acute, several national governments employed measures that were designed to address directly the perceived weakness of demand for smaller families. These measures ranged from fieldworker targets and quotas for enlistment of "new acceptors" of contraception (a strategy employed by many Asian countries) to incentive payments to adopt family planning (Bangladesh, India), to so-called disincentives regarding large families (Singapore), to community pressures to use contraceptives (Indonesia), to outright coercion (China, India in 1976-1977).

Human rights and women's health advocates, as well as many of those promoting voluntary family planning, were appalled by such policies and attacked them with increasing passion through the 1970s and 1980s and into the 1990s. Such policies, they argued, reduced poor people, women in particular, to the role of passive victims of population control policies sponsored by the elite. They argued that rather than working to improve the underlying conditions of the lives of the poor, which would invariably result in a reduced demand for children, policymakers were employing the shortcut of population control policies, violating human rights, and in many cases, actually worsening poor people's living conditions and opportunities to escape from poverty.

In addition, by the 1980s, overwhelming evidence indicated that such fertility reduction measures were unnecessary. The results of numerous community studies and large-scale survey research revealed a demand for family planning services sufficient to bring about substantial declines in fertility. ${ }^{8,13}$ There were also the early success stories of high-quality, voluntary family planning programs in countries like Thailand, Korea, Tunisia, Morocco, Colombia, Mexico and Costa Rica, where rapid and large declines in fertility occurred without use of coercive measures. For example, between 1960-1965 and 1980-1985, the total fertility rate in Thailand declined from 6.4 to 3.0, and in Korea from 5.6 to 2.2.3 Parenthetically, in our view the absence of access to contraception should also be considered a form of coercion, because it frequently condemns women to bearing children they do not wish to have.

As a result of both the outrage inspired by intrusive and unethical policies and the existence of a large unmet need for contraception, the International Conference on Population and Development at Cairo in 1994 explicitly condemned such policies and reiterated the call of earlier population conferences for reproductive health programs, including family planning, to be completely voluntary. The conference went beyond earlier meetings in calling on countries to drop demographic targets and family planning acceptor quotas. Today, nearly all programs around the world respect the right of couples to make informed reproductive choices, free from undue persuasion or coercion. A typical example is the decision by India, shortly after the Cairo conference, to adopt a target-free approach in its reproductive health program (even though method choice remains limited in many parts of the country). An important exception is China, where the one-child policy continues to violate Cairo's reproductive rights standards. Yet the perception lingers that family planning programs throughout the developing world still place undue pressure on families, and particularly on women, to conform to reproductive norms imposed by governments-a perception that is no longer supported by the evidence.

\section{CONCLUSION}

Since the time of Malthus, population growth and what to do about it has been the subject of controversy. Perhaps because at its most fundamental level it deals with sex, it has been a peculiarly incendiary subject of public policy debate. This is no less true today than it was when Malthus wrote more than 200 years ago. Yet much of today's discussion about family planning programs, a principal in- 
strument through which population policies have been implemented over the past 50 years, is based on faulty perceptions and misinformation. Large-scale national family planning responses to unprecedented rates of population growth were an invention of the mid-20th century, and for the most part they have been remarkably successful.

First, family planning programs have had a major and unambiguous impact on fertility rates in many countries. In some countries, fertility fell from very high levels to replacement level within one generation, a previously unheard-of decline that could not have occurred so rapidly in the absence of the modern technologies and delivery systems offered by such programs. ${ }^{21}$ It is also likely that fertility decline, in the absence of family planning policies and programs, would have commenced somewhat later than it actually did in several countries. The second half of the 20th century witnessed a veritable reproductive revolution, supported by unprecedented cooperation between international agencies and governments in the developing world.

Second, despite this success, there are still countries and regions in which high fertility remains a challenge and where progress in raising incomes and improving livelihoods is imperiled by rapid population growth and population pressures on fragile ecosystems. ${ }^{36}$ Foremost among these is much of Sub-Saharan Africa, the world's poorest region, where average fertility remains above five children per woman and declines are slow. Falling fertility elsewhere and low fertility in today's richest countries should not deter us from helping these remaining high-fertility countries to address their large unmet need for contraception.

Third, although the AIDS epidemic has exacted a terrible toll on the prospects of some countries and on millions of families and individuals, its impact on both global demographic rates and even those of the most seriously affected regions is considerably smaller than expected a decade ago. Furthermore, by providing voluntary counseling and testing, and by helping to prevent mother-tochild transmission, family planning programs represent one of the most important avenues for preventing the further spread of the virus that causes AIDS, an avenue that up to this point has been neglected.

Fourth, family planning is highly cost-effective. The cost of averting births is small in comparison with the savings those averted births represent to families and countries. Furthermore, few public health interventions are more important or less expensive than family planning in reducing the morbidity and mortality of mothers, infants and young children. Family planning programs are a development bargain.

Finally, the dilemma that governments faced in trying to balance societal needs against individual reproductive freedom has largely been resolved. Throughout the developing world, and particularly in Africa, there is a large, empirically verified demand-much of which remains unmet-for family planning services for both spacing and preventing future births. High-quality, voluntary family planning programs benefit women and children and are effective in re- ducing fertility, thus benefiting society. Morally unacceptable policies designed to pressure or compel people to limit their fertility have been shown to be unnecessary and thus have been abandoned, except in China.

Unfortunately, funding for family planning programs has faltered for more than a decade. Between 1995 and 2008, while funds committed by donors and developing countries to HIV and AIDS programming increased by nearly $300 \%$, funds devoted to family planning declined by some $30 \% .{ }^{27}$ As a result, many countries are less able to provide family planning services today than they were a decade ago, and much of the earlier commitment has waned. There are indications that fertility declines are leveling off or even being reversed in some countries.

Why does this matter? Women and children continue to suffer and die as a consequence of unwanted and unintended childbearing. Beyond that are renewed concerns about a variety of environmental issues and about the security of nations and the stability of governments, as well as deepening worries about food security and pervasive poverty. In the face of declining political and financial commitment to family planning programs, we must address head-on the faulty criticisms that have held back efforts to satisfy the unmet demand for family planning services. High fertility and rapid population growth remain real problems that merit our attention and action.

\section{REFERENCES}

1. Ehrlich PR and Ehrlich AH, One with Nineveh: Politics, Consumption, and the Human Future, Washington, DC: Island Press, 2005

2. Lomborg B, The Skeptical Environmentalist: Measuring the Real State of the World, Cambridge, UK: Cambridge University Press, 2001.

3. United Nations (UN), World Population Policies 2007, New York: United Nations, 2007.

4. Birdsall N, Allen K and Sinding S, eds., Population Matters: Demographic Change, Economic Growth, and Poverty in the Developing World, Oxford: Oxford University Press, 2001.

5. Cincotta R, Engelman R and Anastasion D, The Security Demographic: Population and Civil Conflict After the Cold War, Washington DC: Population Action International, 2003.

6. Cincotta R, How democracies grow up, Foreign Policy, March/April 2008, pp. 80-82.

7. National Commission on Terrorist Attacks, The 9/11 Commission Report: Final Report of the National Commission on Terrorist Attacks upon the United States, New York: W. W. Norton \& Company, 2004.

8. Casterline J and Sinding SW, Unmet need for family planning in developing countries and implications for population policy, Population and Development Review, 2000, 26(4):691-723.

9. Cleland J et al., Family planning: the unfinished agenda, Lancet, 2006, 368(9549): 1810-1827.

10. Millennium development goals indicators, <http://mdgs.un.org/ unsd/mdg/Host.aspx?Content=Indicators/OfficialList.htm>, accessed Feb. 26, 2009 .

11. Speidel J, Funds for family planning and reproductive health, paper presented at the International Parliamentarians Conference on the Implementation of the ICPD Programme of Action, Bangkok, Nov. 21-22, 2006.

12. Campbell White A, Merrick RW and Yazbeck AS, Reproductive Health: The Missing Millennium Development Goal, Washington, DC: World Bank, 2006

13. Singh S et al., Adding It Up: The Benefits of Investing in Sexual and 
Reproductive Health Care, New York: Alan Guttmacher Institute, 2003.

14. Pritchett L, Desired fertility and the impact of population policies, Population and Development Review, 1994, 20(1):1-55.

15. Connelly M, Fatal Misconception: The Struggle to Control World Population, Cambridge, MA, USA, and London: Belknap Press of Harvard University Press, 2008.

16. Becker GS, An economic analysis of fertility, in: Demographic and Economic Change in Developed Countries: A Conference of the UniversitiesNational Bureau Committee for Economic Research, Princeton, NJ, USA: Princeton University Press, 1960, pp. 209-231.

17. Schultz TW, The value of children: an economic perspective, The Journal of Political Economy, 1973, 81(2 Part II):S2-S13

18. Cleland J et al., The Determinants of Reproductive Change in Bangladesh: Success in a Challenging Environment, Washington, DC: World Bank, 1994

19. National Institute of Population Research and Training (NIPORT), Mitra and Associates, and ORC Macro, Bangladesh Demographic and Health Survey 2004, 2005, Dhaka, Bangladesh: National Institute of Population Research and Training and Mitra and Associates; and Calverton, MD, USA: ORC Macro.

20. Roudi-Fahimi F, Iran's Family Planning Program: Responding to a Nation's Needs, MENA Policy Brief, Washington, DC: Population Reference Bureau, 2002

21. Bongaarts J, The role of family planning programmes in contemporary fertility transitions, in: Jones GW et al., eds., The Continuing Demographic Transition, Oxford: Clarendon Press, 1997, pp. 422-444.

22. Sen A, Development as Freedom, New York:Alfred Knopf, 1999.

23. Summers L, The most influential investment, Scientific American, 1992, 267(2):108

24. Schultz TP, Human capital, family planning and their effects on population growth, American Economic Review, 1994, 84(2):255-260.
25. Eberstadt N, Doom and demography, The Wilson Quarterly, Winter 2006, pp. 27-31.

26. Wattenberg BJ, The population explosion is over, New York Times Magazine, Nov. 23, 1997, pp. 60-63.

27. Bongaarts J, Fertility transitions in the developing world: progress or stagnation? Studies in Family Planning, 2008, 39(2):106-110.

28. Mosher S, AIDS and population control in Africa, Population Research Institute Weekly Briefing, 2000, 2(16):1-3.

29. The Joint United Nations Programme on HIV/AIDS (UNAIDS), AIDS Epidemic Update: December 2007, Geneva: UNAIDS, 2007.

30. Bongaarts J, Has the AIDS epidemic peaked? Population and Development Review, 2008, 14(2):199-224.

31. Vlassoff $\mathrm{M}$ et al., Assessing costs and benefits of sexual and reproductive health interventions, Occasional Report, New York: The Alan Guttmacher Institute, 2004, No. 11.

32. Jamison DT et al., Disease Priorities in Developing Countries, Oxford, UK: Oxford University Press, 2006.

33. Mosher S, Population Control-Real Costs, Illusory Benefits, Edison NJ, USA: Transaction Publishers, 2008

34. Berelson B and Freedman R, The record of family planning programs, Studies in Family Planning, 1976, 7(1):1-40.

35. Wyon JB and Gordon JE, The Khana Study: Population Problems in the Rural Punjab, Cambridge, MA, USA: Harvard University Press, 1971.

36. Alexandratos N, Countries with rapid population growth and resource constraints: issues of food, agriculture, and development, Population and Development Review, 2005, 31(2):237-258.

Author contact:JBongaarts@popcouncil.org 